\title{
Gender differences in health of EU10 and EU15 populations: the double burden of EU10 men
}

\author{
W. J. Nusselder $\cdot$ C. W. N. Looman • \\ H. Van Oyen $\cdot$ J. M. Robine $\cdot$ C. Jagger
}

Published online: 4 November 2010

(c) The Author(s) 2010. This article is published with open access at Springerlink.com

\begin{abstract}
This study compares gender differences in Healthy Life Years (HLY) and unhealthy life years (ULY) between the original (EU15) and new member states (EU10). Based on the number of deaths, population and prevalence of activity limitations from the Statistics of Living and Income Conditions Survey (SILC) survey, we calculated HLY and ULY for the EU10 and EU15 in 2006 with the Sullivan method. We used decomposition analysis to assess the contributions of mortality and disability and age to gender differences in HLY and ULY. HLY at age 15 for women in the EU10 were 3.1 years more than those for men at the same age, whereas HLY did not differ by gender in the EU15. In both populations ULY at age 15 for women exceeded those for men by 5.5 years. Decomposition showed that EU10 women had more HLY because higher
\end{abstract}

Communicated by Dorly J.H. Deeg.

W. J. Nusselder $(\bowtie) \cdot C$. W. N. Looman

Department of Public Health, Erasmus MC, University Medical

Center Rotterdam, PO Box 2040, 3000 CA Rotterdam,

The Netherlands

e-mail: w.nusselder@erasmusmc.nl

H. Van Oyen

Scientific Institute of Public Health, Brussels, Belgium

J. M. Robine

French Institute of Health and Medical Research, INSERM,

Paris Cedex, France

C. Jagger

Department of Health Sciences, University of Leicester, 22-28

Princess Road West, Leicester LE1 6TP, UK

C. Jagger

Institute for Ageing and Health, Newcastle University, Campus for Ageing and Vitality, Newcastle upon Tyne NE4 5PL, UK disability in women only partially offset $(-0.8$ years) the effect of lower mortality ( +3.9 years). In the EU15 women's higher disability prevalence almost completely offset women's lower mortality. The 5.3 fewer ULY in EU10 men than in EU10 women mainly reflected higher male mortality (4.5 years), while the fewer ULY in EU15 men than in EU15 women reflected both higher male mortality (2.9 years) and higher female disability (2.6 years). The absence of a clear gender gap in HLY in the EU15 thus masked important gender differences in mortality and disability. The similar size of the gender gap in ULY in the EU-10 and EU-15 masked the more unfavourable health situation of EU10 men, in particular the much stronger and younger mortality disadvantage in combination with the virtually absent disability advantage below age 65 in men.

Keywords Health expectancy $\cdot$ Life expectancy $\cdot$ Healthy life years $\cdot$ Gender differences

\section{Introduction}

Women live longer than men. This is not a new phenomenon as in the eighteenth century when time series on life expectancy began in Sweden, a gender difference in life expectancy at birth of almost 3 years in favour of women was found (Human Mortality Database 2010, http://www. mortality.org/). Similar gender gaps were present in European countries where time series started in the nineteenth century (France, Denmark, Netherlands, Belgium and Norway), except for Belgium where life expectancy at birth of men and women was equal (Human Mortality Database 2010, http://www.mortality.org/). In the course of the twentieth century, the overall mortality reduction was 
more beneficial for women and resulted in a substantial widening of the male-female longevity gap. In the low mortality countries, this tendency has reversed in the last decades (European Observatory on the Social SituationDemography Network 2009b). Until today, life expectancy of women exceeds that of men, although the size of the gender gap varies between populations (Jagger et al. 2008; Commission of the European Communities 2009).

The longer life expectancy of women may suggest that women are healthier than men. However, substantial evidence exists that women report worse self-rated health, more health problems, more frequent disability and use more health services, both in terms of hospitalisation and medications than same-aged men throughout life (Verbrugge 1989; Crimmins et al. 1996; Leveille et al. 2000; Case and Paxson 2005; Oksuzyan et al. 2008, 2009). This mortality advantage and health disadvantage is known as the 'health-survival' paradox (Oksuzyan et al. 2008). For a comprehensive assessment of health, in particular gender differences in health, it is important to consider both survival and health, rather than looking at either life expectancy or the health status of the population.

Health expectancy indicators, that combine mortality and morbidity data into a single composite indicator, are increasingly used to assess the health of populations or population groups (Robine et al. 1992, 2003; Robine and Jagger 2003). Health expectancy indicators share important attractive properties with life expectancy, such as their measurement in expected years of life and their independence from the age structure of the population, if small age intervals are used. An additional attractive feature is that health expectancy takes into account both mortality and the health status of the surviving population and thus provides information on the length of life (adding years to life), and the healthfulness of life (adding life to years). A wellknown example is the disability-free life expectancy (DFLE). DFLE indicates how many years of the total life expectancy a person of a given age can expect to live without disability, and the difference between the total life expectancy and the DFLE is the life expectancy with disability. Different variants of DFLE exist, depending on how disability is measured.

Healthy Life Years (HLY) or the expected life years without activity limitations, which was selected in 2004 to be one of the structural indicators of the EU (European Commission 2010), combines information on mortality with disability based on the global activity limitation index (GALI). The GALI aims to capture long-term limitation (at least 6 months) in usual activities, caused by ill-health and includes three severity levels: not limited, limited but not severely, and severely limited (Van Oyen et al. 2006). Detailed information on Health Expectancies in Europe, including HLY for all EU member states is available from the European Health Expectancy Monitoring Unit (http:// www.ehemu.eu/) and the general public website devoted to HLY (http://www.healthy-life-years.eu/). HLY differ substantially between EU member states and within member states (e.g., between men and women). Most striking is the gap between the original (EU15) member states (Austria, Belgium, Denmark, Finland, France, Germany, Greece, Ireland, Italy, Luxembourg, the Netherlands, Portugal, Spain, Sweden and United Kingdom) and the new EU (EU10) member states that joined after 2004 (Cyprus, Czech Republic, Estonia, Hungary, Latvia, Lithuania, Malta, Poland, Slovakia and Slovenia). HLY in women at age 50 were 1.5 years lower in the pooled EU10 countries than in the pooled EU15 countries, and this disadvantage was 3 years in men (Jagger et al. 2008).

Reducing inequalities in HLY within member states receives high priority on the EU (European Commission 2009) and national policy agendas (VWS 2008), both from an equity point of view and because improving health of the disadvantaged group may improve health of the population at large. To reduce inequalities, insight is needed into the underlying causes of the inequalities, as these may point at possible interventions, either at the societal or the individual level, to reduce them. A first step is assessing to what extent differences in HLY are due to differences in mortality and disability, and at which ages these differences occur. In mortality research, decomposition (i.e., partitioning) techniques have been widely used to assess the contribution that age groups make to differences in life expectancy (Arriaga 1984; Pollard 1988) including gender disparities in life expectancy (Bah 1998; Trovato and Lalu 1998; Nusselder and Looman 2004). Similar tools are now available to partition differences in health expectancy into additive contributions of mortality versus disability differences and of age groups (Andreev et al. 2002; Nusselder and Looman 2004). For the Netherlands, using these tools has revealed that DFLE did not differ between men and women because the effect of higher prevalence of disability in women, reducing DFLE, and lower mortality, increasing DFLE, largely compensated each other (Nusselder and Looman 2004). But the same study also showed that due to the combination of the higher prevalence of disability and lower mortality women spent substantially more years with disability than men.

The aim of the current study is to describe and compare gender differences in HLY and unhealthy life years (ULY), defined as the expected life years with activity limitations, in the pooled EU10 and EU15 populations, and to explain differences in the overall patterns by looking at the contribution of mortality and disability differences and of different age groups. 


\section{Data and methods}

Data

We obtained age and sex-specific data on the number of deaths (2006), the population $(2006,2007)$ and prevalence of activity limitation (2006) for each EU member state from the European Health Expectancy Monitoring Unit (EHEMU) Information System (http://www.ehemu.eu/).

Death counts and population estimates for each member state originate from the EUROSTAT database (http://epp. eurostat.ec.europa.eu/), except for France and Italy where death counts were directly collected by EHEMU from the national statistical offices (INSEE and ISTAT, respectively).

The number of persons with activity limitations and total numbers in the sample by age, sex for each member state were derived by EHEMU from the Statistics of Living and Income Conditions Survey (SILC) in 2006. The SILC survey was first conducted in all EU25 countries in 2005, on individuals aged 16 years and over. The cross-sectional SILC that was used for this study was based on nationally representative probability samples of the population residing in private households within the country, irrespective of language or nationality. The SILC survey in 2006 covers a sample in total of 375,243 participants (235,835 in EU15 and 139,408 in EU10), of which 369633 responded to the GALI question (233 391 in EU15 and 136 242 EU10). Overall non-response rate averaged over countries is somewhat above $20 \%$. There is a large variation around this average among the countries, with the non-response rate varying from $5 \%$ in Cyprus to $40 \%$ in Denmark and Belgium (EUROSTAT 2009). What distinguishes EU-SILC from prior EU surveys, such as the European Community Household Panel (ECHP), is its organisation under a framework Regulation instead of a gentlemen's agreement. This implies that the survey is compulsory for all EU Member States, and is based on a common 'framework', which is defined by: harmonised lists of target variables, a recommended design for implementing EU-SILC, common requirements for imputation, weighting, sampling error calculation, and common concepts (household and income) and classifications (Eurostat 2007). For more information on EU-SILC, see: http://circa. europa.eu/Public/irc/dsis/eusilc/library.

\section{Activity limitation}

SILC contains the Minimum European Health Module (MEHM), devised by the Euro-REVES group (Robine and Jagger 2003), which includes a disability measure, the global activity limitation index (GALI). The GALI instrument ('For at least the last 6 months, have you been limited because of a health problem in activities people usually do?') aims to capture long-term limitation ( $>6$ months) in usual activities, caused by ill-health with three severity levels: none, limited but not severely and severely limited (except for Denmark where there were only two response categories: limited or not). The reliability and validity of the GALI have already been reported (Van Oyen et al. 2006; Cox et al. 2009; Jagger et al. 2010), respectively. People were considered to be disabled (unhealthy) in our study, when they reported any limitation (not severely and severely).

\section{EU10 versus EU15}

We divided the EU member states into two groups: EU15, including EU member states before May 2004 and EU10, including the new member states joining the EU in May 2004. The EU15 consists of: Austria (AT), Belgium (BE), Denmark (DK), Finland (FI), France (FR), Germany (DE), Greece (GR), Ireland (IE), Italy (IT), Luxembourg (LU), the Netherlands (NL), Portugal (PT), Spain (ES), Sweden (SW) and United Kingdom (UK). The EU 10 consists of: Cyprus (CY), Czech Republic (CZ), Estonia (ET), Hungary (HU), Latvia (LV), Lithuania (LT), Malta (MT), Poland (PL) Slovakia (SK) and Slovenia (SL). Romania and Bulgaria were not included because they did not join the EU until 2007.

\section{Methods}

\section{Sullivan life table analyses}

HLY is the number of years a person of a given age can expect to live free of activity limitations. For each gender and for the pooled EU10 and EU15 populations separately, the HLY indicator was calculated using Sullivan's method (Sullivan 1971; Jagger 1999). The Sullivan method uses the prevalence of disability in each age group to divide the number of person-years into years with and without disability (Jagger 1999). The number of person-years by age was calculated from age-specific mortality rates using standard life table techniques, assuming that deaths occur on average in the middle of the age interval (linear assumption). Multiplying the number of person-years in each age group with the proportion disabled in that age group gives the number of person-years in each age group with disability. Summing the number of person-years with disability from the age ' $a$ ' at which the life expectancy is calculated until the last age group gives the total number of years lived with disability lived after age ' $a$ '. Dividing this number by the total number of persons alive at age ' $a$ ' gives the ULY at age ' $a$ '. The number of HLY is obtained 
by subtracting the ULY from the total life expectancy (or using 1 minus the proportion disabled in the above mentioned approach). It is noteworthy that each age group contributes to the number of disabled years, although older age groups, where the prevalence of disability is higher, contribute more than younger age groups. We present HLY and ULY, and their sum the total life expectancy (LE) at age 15,50 and 65 years.

\section{Decomposition analysis}

The contribution of the mortality and disability effects, and of different age groups, are assessed by using a decomposition tool which partitions the gender differences in health expectancy into additive contributions (Nusselder and Looman 2004). This technique is based on the Sullivan method to calculate health expectancy and is an extension of the Arriaga method (Arriaga 1984) to decompose differences in total life expectancy. The decomposition tool first decomposes the difference (or change) in health expectancy at age ' $a$ ' into mortality and disability effects. The mortality effect is the difference in health expectancy due to a difference in the number of person-years lived caused by a difference in total mortality up to and including that age. The disability effect is the difference in health expectancy due a change in the proportion with disability. The mortality effect is further decomposed by age using an adjustment of the Arriaga method. If data on disability and mortality by cause are available, further decomposition by cause is possible with the tool. The decomposition tool is described in more detail elsewhere (Nusselder and Looman 2004). All analyses were performed in R (http://www.r-project.org/). User-friendly software for decomposition of differences in life and health expectancy by age, mortality and disability and causes of death and disability is available from the author on request.

\section{Results}

LE, HLY and ULY at age 15, 50 and 65

in the EU10 and EU15

In the EU15 women aged 15 could expect to live a further 68.5 years, of which 48.4 years $(71 \%$ of their remaining life expectancy) were free of activity limitation, whilst HLY at age 15 for men were 48.4 years, $77 \%$ of their remaining life expectancy of 62.9 years (Table 1 ). ULY at age 15 were 20.1 years for women and 14.6 years for men in the EU15. The health picture for the EU10 was substantially less favourable than for the EU15. In the EU10, women aged 15 could expect to live a further 64.7 years, of which 45.8 years $(71 \%)$ were free of activity limitations, whilst HLY for men in the EU10 were 42.7 years $(76 \%$ of their remaining life expectancy of 56.3 years). ULY at age 15 in the EU10 were 18.9 years for women and 13.6 years for men. The EU10 disadvantage was also present at older ages (Table 1), indicating systematic differences in life and health expectancies between the EU10 and EU15 populations.

\section{Gender differences in HLY}

The pooled EU10 population not only had worse health compared to the pooled EU15 population, but gender differences were also larger. HLY at age 15 for women in the EU10 exceeded those of men of the same age by 3.1 years, while in the EU15 HLY at age 15 did not differ between men and women. At age 50 and age 65, the gender gaps in HLY were still small in the EU15 (0.2 years at age 50 and 0.2 years at age 65) whilst in the EU10 they decreased from 3.1 years at age 15 , to 1.7 years at age 50 and 0.4 years at age 65 .

Decomposition of the gender gap in HLY partitions the gender difference into the contribution made by differences in mortality and by differences in the prevalence of

Table 1 Healthy Life Years (HLY), Unhealthy Life Years (ULY) and total life expectancy (LE), and proportion of life expectancy spent free of disability (\% HLY/LE) at age 15, 50 and 65

\begin{tabular}{|c|c|c|c|c|c|c|c|c|c|c|c|c|}
\hline & \multicolumn{4}{|l|}{ Age 15} & \multicolumn{4}{|l|}{ Age 50} & \multicolumn{4}{|l|}{ Age 65} \\
\hline & $\begin{array}{l}\text { HLY } \\
\text { (years) }\end{array}$ & $\begin{array}{l}\text { ULY } \\
\text { (years) }\end{array}$ & $\begin{array}{l}\text { LE } \\
\text { (years) }\end{array}$ & $\begin{array}{l}\text { HLY/LE } \\
(\%)\end{array}$ & $\begin{array}{l}\text { HLY } \\
\text { (years) }\end{array}$ & $\begin{array}{l}\text { ULY } \\
\text { (years) }\end{array}$ & $\begin{array}{l}\text { LE } \\
\text { (years) }\end{array}$ & $\begin{array}{l}\text { HLY/LE } \\
(\%)\end{array}$ & $\begin{array}{l}\text { HLY } \\
\text { (years) }\end{array}$ & $\begin{array}{l}\text { ULY } \\
\text { (years) }\end{array}$ & $\begin{array}{l}\text { LE } \\
\text { (years) }\end{array}$ & $\begin{array}{l}\text { HLY/LE } \\
(\%)\end{array}$ \\
\hline EU15 men & 48.4 & 14.6 & 62.9 & 76.9 & 18.4 & 11.4 & 29.8 & 61.6 & 9.0 & 8.5 & 17.5 & 51.5 \\
\hline EU15 women & 48.4 & 20.1 & 68.5 & 70.7 & 18.6 & 15.9 & 34.5 & 53.9 & 9.2 & 11.9 & 21.1 & 43.7 \\
\hline Difference & 0.0 & 5.5 & 5.5 & -6.2 & 0.2 & 4.4 & 4.7 & -7.7 & 0.2 & 3.4 & 3.6 & -7.8 \\
\hline EU10 men & 42.7 & 13.6 & 56.3 & 75.8 & 13.8 & 10.7 & 24.5 & 56.2 & 6.4 & 7.8 & 14.3 & 45.0 \\
\hline EU10 women & 45.8 & 18.9 & 64.7 & 70.8 & 15.5 & 15.5 & 31.0 & 50.0 & 6.9 & 11.5 & 18.4 & 37.4 \\
\hline Difference & 3.1 & 5.3 & 8.4 & -5.0 & 1.7 & 4.8 & 6.5 & -6.3 & 0.4 & 3.7 & 4.1 & -7.7 \\
\hline
\end{tabular}


Table 2 Decomposition of the gender gap in Healthy Life Years (HLY), Unhealthy Life Years (ULY) and total life expectancy (LE) by effect, at age 15 for men and women

\begin{tabular}{lccccccc}
\hline Age 15 & EU15 & & & & EU10 & & \\
\cline { 2 - 3 } & HLY & ULY & LE & & HLY & ULY & LE \\
\hline Men & 48.4 & 14.6 & 62.9 & & 42.7 & 13.6 & 56.3 \\
Women & 48.4 & 20.1 & 68.5 & & 45.8 & 18.9 & 64.7 \\
Difference & & & & & & \\
$\quad$ Women-Men & 0.02 & 5.5 & 5.5 & & 3.1 & 5.3 & 8.4 \\
Decomposition of difference & & & & & \\
$\quad$ Mortality effect & 2.6 & 2.9 & 5.5 & 3.9 & 4.5 & 8.4 \\
Disability effect & -2.6 & 2.6 & 0.0 & -0.8 & 0.8 & 0.0 \\
Total & 0.02 & 5.5 & 5.5 & 3.1 & 5.3 & 8.4 \\
\hline
\end{tabular}

disability. It shows that the 3.1 extra HLY that women in the EU10 could expect to live compared to men were largely caused by women's lower mortality (+3.9 HLY) (Table 2). Women lived longer and, ceteris paribus, lived longer free of disability. But also the age-specific prevalence of disability in women was higher than in men. This yielded 0.8 fewer HLY. In the EU15, the effect of women's lower mortality (increasing HLY by 2.6 years) was almost completely nullified by the higher disability prevalence (reducing HLY by 2.6 years); hence the number of HLY was similar for EU15 men and women.

The gender gap in HLY reduced with increasing age in the EU10 (Fig. 1a), reflecting a decreasing mortality effect in contrast to the disability effect, which did not decrease with age. In the EU15, both the disability and mortality effects decreased gradually with age.

\section{Gender differences in ULY}

In both the pooled EU10 and EU15 populations, for women at age 15 ULY were 5.5 years more than for men (Table 1). At older ages the gender gap in ULY was also similar in the EU10 and EU15; at age 50, the gap was 4.8 years in the EU10 and 4.4 years in the EU15 and at age 603.7 and 3.4 years, respectively (Table 1).

Decomposition of gender differences in ULY showed that the contribution of the mortality and disability effects differed substantially between the EU10 and EU15 populations. At age 15, the gender gap in ULY in the EU10 was mainly the result of men's higher mortality ( 4.5 years) whilst their lower disability only explained 0.8 fewer ULY (Table 2). In the EU15, men also lived 5.5 fewer ULY than women, but in this population the lower ULY reflected a combination of higher mortality (2.9 years) and lower
Fig. 1 a Decomposition of the gender gap in Healthy Live Years (HLY) at age 15, 50 and 65 into mortality and disability effects in pooled EU15 and EU10 populations.

b Decomposition of gender gap in Unhealthy Live Years (ULY) at age 15,50 and 65 into mortality and disability effect in pooled EU15 and EU10 populations a

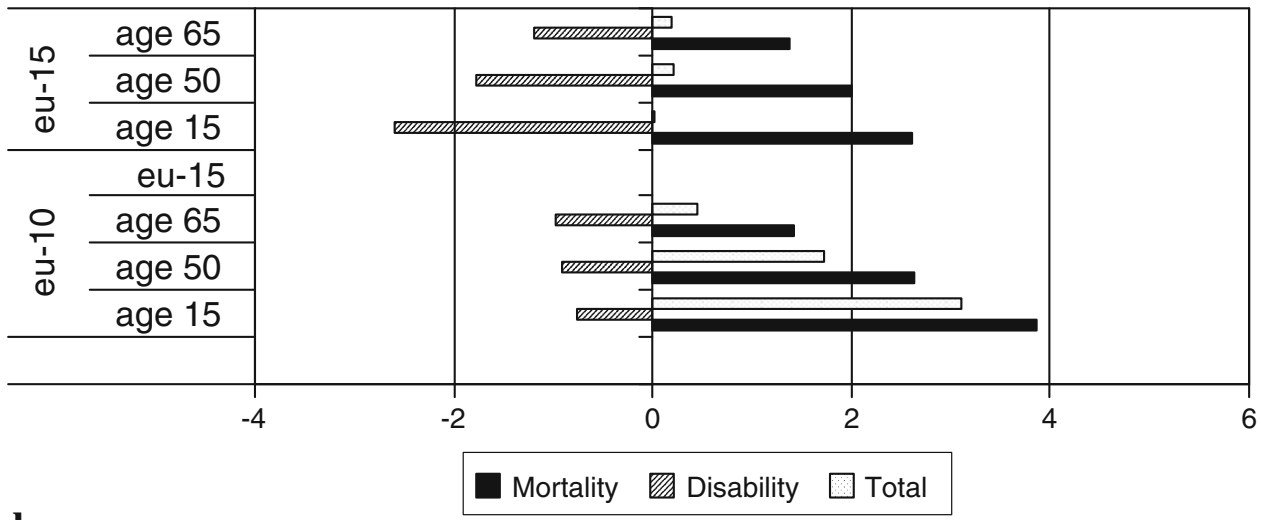

b

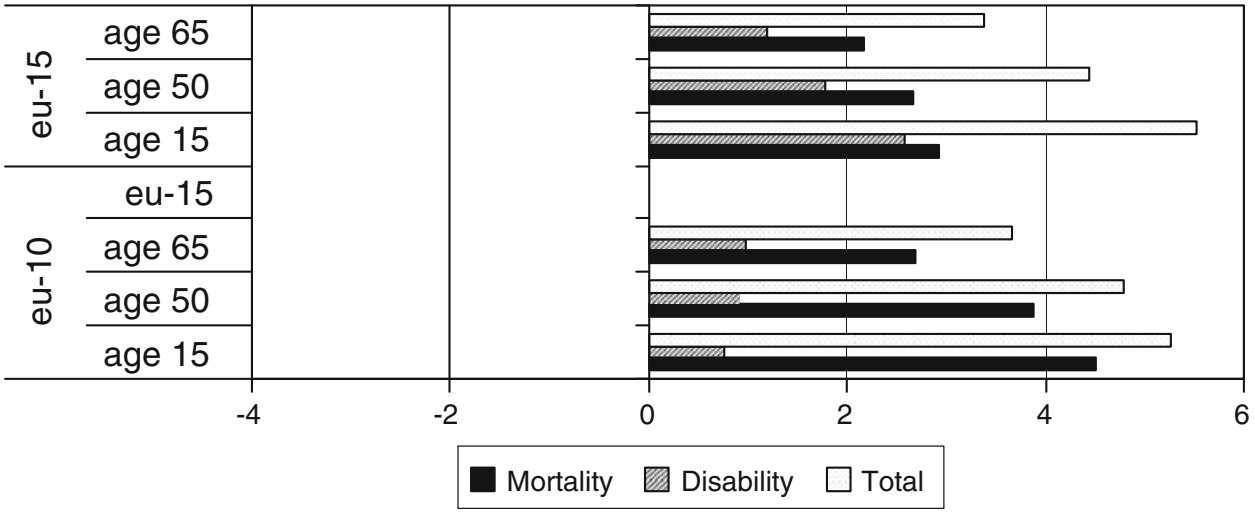


Fig. 2 a Decomposition of the gender gap in Unhealthy Live Years (ULY) at age 15 into mortality and disability effects and by age, pooled EU15 population. b Decomposition of the gender gap in Unhealthy Live Years (ULY) at age 15 into mortality and disability effects and by age, pooled EU10 population
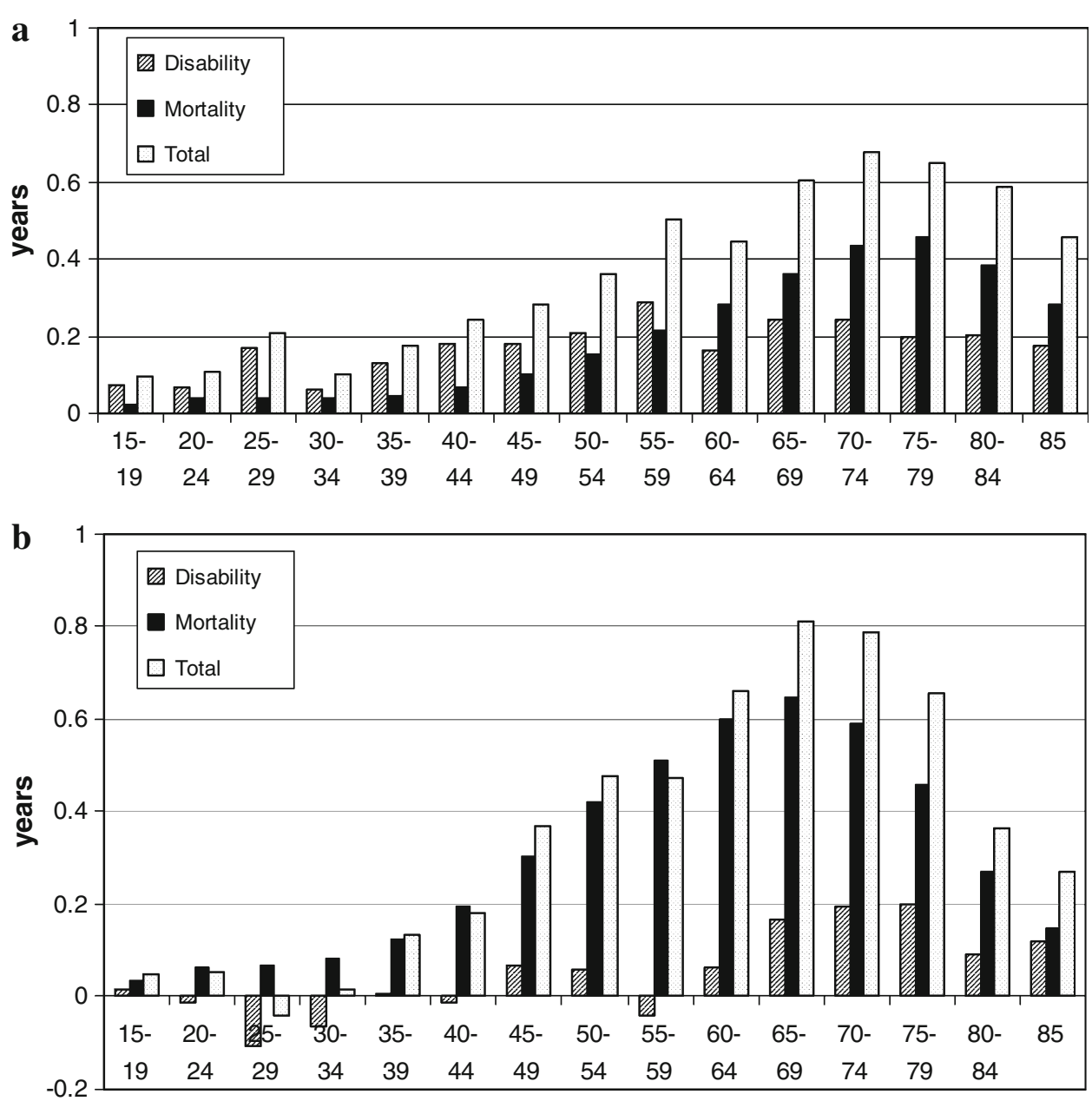

disability ( 2.6 years) in men. At older ages the patterns were similar to younger ages (Fig. 1b).

Comparison of the contribution of different age groups to the gender differences in ULY, and the mortality and disability effects between the EU10 and EU15 populations, showed a disability advantage in EU15 men at all ages, while for the EU10 this was seen only at older ages (Fig. 2b). In addition the mortality disadvantage in EU10 men occurred at younger ages than in the EU15 population.

\section{Discussion}

Both in the pooled EU10 and EU15 populations, women live longer than men, but women also spend more years and a larger proportion of their remaining life expectancy with disability. The gender gap in HLY, however, differs between the two populations. While in the EU15 population the gender gap in HLY is virtually absent, it is more than 3 years in the EU10 population. Our study thus shows that the health-survival paradox is present in both the EU10 and EU15 populations, but it also points at clear differences in the overall patterns of the gender gaps. In the EU10 the male mortality disadvantage is larger. Additionally, the commonly found disability advantage in men appears to be much smaller in EU10 males, and is virtually absent below age 65. Hence EU10 males face a double disadvantage: higher mortality than EU10 females and EU15 males and a smaller disability advantage than EU15 males. As a result, EU10 men not only have a shorter total life expectancy, but also the number of HLY is substantially lower than in women of the same age. In the EU15 population, this male disadvantage in HLY is not found.

A potential limitation of our study relates to using selfreported disability data from one single question in surveys of the non-institutionalised population. As medical or other registrations generally do not include information on disability, surveys are the standard source of disability information. Disability in large-scale surveys is mostly self-reported; only a few surveys and none that are across all EU countries include performance-based measures of disability. Relying on self-reports of disability may have biased our results, in particular because reporting behaviour may differ between men and women. However, 
comparing self-reports with performance measures confirms that women are truly more disabled than men (Merrill et al. 1997).

Using one single question to assess disability may have introduced bias, although we expect this to be less than that from using all non-harmonised disability measures, particularly since a previous validation study showed that the GALI question has an acceptable reliability (Cox et al. 2009). In addition, another recent study comparing the GALI with other disability measures, showed that the GALI appears to satisfactorily reflect levels of function and disability as assessed by longer-standing objective and subjective measures, both across Europe and in a similar way between countries (Jagger et al. 2010). The international comparability of the disability measures in our study is better than earlier efforts to obtain EU wide disability measures, including the ECHP. However, the SILC 2006 is still not fully comparable between the countries (Ekholm and Bronnum-Hansen 2009). In particular for Germany and Denmark the GALI question is not comparable to those in other countries. We reran our analyses excluding these two countries, but found no differences in our results. Excluding the institutionalised population may also have affected our results, as the rate of institutionalisation is known to differ by gender. However, given the higher institutionalisation rate in women, we expect that if anything, our conclusion on the double disadvantage in EU10 men as compared to EU10 women would become stronger if we had included data among the institutionalised population.

Some limitations of the methods need to be considered. The calculation of HLY and the decomposition of HLY are based on the Sullivan method. The Sullivan method is the standard way to calculate health expectancy on a routine basis, however, it does not produce a pure period indicator such as (period) life expectancy. While the deviation from a pure period indicator can introduce bias (Barendregt et al. 1994; Van de Water et al. 1995; Mathers and Robine 1997), this should not be important for comparisons between population groups. Regarding the decomposition method, it is noteworthy that the tool identifies the extent to which differences in disability prevalence and total mortality (in each age group) contribute to health expectancy differences. It cannot assess the contribution of underlying flows, such as incidence of disability and recovery from disability (Nusselder and Looman 2004).

Another limitation is that our study treated the pooled EU10 and EU15 population as homogeneous groups, ignoring differences between the member states within each groups (Jagger et al. 2008; Commission of the European Communities 2009). The results of our study can therefore not be generalised to specific member states, but serves to understand better the overall picture. The next step will be to assess the variation in gender gaps within individual member states, and to assess which countries do and do not fit to the general picture.

Our study confirms the presence of the health-survival paradox (Case and Paxson 2005; Oksuzyan et al. 2009); both in the EU10 and EU15 populations women do live longer but spend more years with disability. There are different explanations for this paradox. One explanation is that women are healthier than men, but simply report more health problems in surveys than men. Possible reasons for differences in reporting are that women are more likely to factor less serious ailments into their reports of poor health (Spiers et al. 2003), or that men are more reluctant to participate and/or accurately report in surveys if they have disabilities or diseases (Oksuzyan et al. 2009). There is substantial evidence that the health-survival paradox is not just an artefact. For instance, observed performance of physical tasks confirms that women have more disability than men of the same age (Merrill et al. 1997). A recent study of Oksuyan (Oksuzyan et al. 2009) found that the contribution of selection bias due to lower participation of men when they have ill-health or disability, is likely to be small. The same study also found no evidence for sexspecific reporting of medication use. The second explanation is that women do have higher morbidity than men, and explanations include: a negative impact of estrogen and the second X chromosome, differences in the immune system to avoid the harmful effects of infections, a relatively higher compatibility of sick roles with other female responsibilities, engagement in more risk taking behaviour among men, as well as better awareness of disease symptoms, and timely seeking for medical advice (for an overview, see: Oksuzyan et al. 2009). Also the lower peak bone mass in women, accelerated bone loss beginning at menopause and less muscle strength in women may contribute to gender differences (Leveille et al. 2000). These factors may have resulted in gender differences in the distributions of chronic conditions (Verbrugge 1989; Case and Paxson 2005). Women are more likely than men to have non-fatal diseases, such as arthritis, whereas men are more likely to have conditions such as cardiovascular disease (CVD) or respiratory conditions with high case-fatality (Leveille et al. 2000). Additionally, these factors may have resulted in men having higher chances of experiencing hospital episodes and dying from the same chronic conditions, implying that men may experience more severe forms of these conditions.

A novel finding is that the pattern of gender differences varies between the EU10 and EU15 populations. In particular, in the EU10 the much stronger and younger mortality disadvantage (of the 8.4 years gap in life expectancy 5.1 years originates below age 65 ) in men, in combination with the virtually absent disability advantage below age 65 , 
is striking. A possible explanation for this unfavourable situation is the rapid economic transition in the former communist states. According to McKee (McKee and Shkolnikov 2001) young men were especially vulnerable to the consequences of the policies pursued by the communist regimes in eastern Europe before 1990 and the ensuing transition. The leading causes of high mortality in these countries, in particular among men were injuries and violence, cardiovascular diseases and cancers (McKee and Shkolnikov 2001; European Observatory on Social Situation and Demography 2009a). High levels of alcohol consumption, especially binge drinking, were the main contributors to the high mortality from these causes in men, as did smoking and poor nutrition, but to a lesser extent (McKee and Shkolnikov 2001). Also the lower quality of medical care in the former Central and Eastern European Countries may have contributed to the more unfavourable position of EU10 men. A study of Newey et al. (2003) not only showed a clear gender gap in preventable mortality in the new member states, but also indicated that treatable mortality, i.e., from causes that are responsive to medical intervention, through secondary prevention and treatment, was higher in men than in women in this region.

Our study has important implications. First, given the health-survival paradox, gender differences in health should be assessed by health indicators that take into account both mortality and morbidity. Additionally both healthy and unhealthy years need consideration. The gender gap in HLY masks important gender differences in mortality and disability within the EU15, while the similar size of the gender gap in ULY in the EU10 and EU15 masks the more unfavourable position of EU10 men, both due to higher mortality and a smaller disability advantage as compared to EU10 women and EU15 men. Second, the dire situation of men in the EU10, in particular below age 65 , may have important consequences for their ability to contribute fully in society, and may preclude men from participating fully in working life, family life and society.

Acknowledgments This study was supported by the European Public Health Programme (EHLEIS Project Grant Number 2006 109).

\section{Conflict of interest None.}

Open Access This article is distributed under the terms of the Creative Commons Attribution Noncommercial License which permits any noncommercial use, distribution, and reproduction in any medium, provided the original author(s) and source are credited.

\section{References}

Andreev E, Shkolnikov V et al (2002) Algorithm for decomposition of differences between aggregate demographic measures and its application to life expectancies, healthy life expectancies, parity progression ratios and total fertility rates. Demographic Research 7:499-522

Arriaga EE (1984) Measuring and explaining the change in life expectancies. Demography 21(1):83-96

Bah SM (1998) Assessing the contribution of age-sex differentials in causes of death due to infectious and parasitic diseases to the trends in age-sex differentials in life expectancy in Mauritius. Soc Biol 45(3-4):260-272

Barendregt JJ, Bonneux L et al (1994) Health expectancy: an indicator for change? J Epidemiol Community Health 48(5): $482-487$

Case A, Paxson C (2005) Sex differences in morbidity and mortality. Demography 42(2):189-214

Commission of the European Communities (2009) Solidarity in health: Reducing health inequalities in the EU, Commission of the European Communities

Cox B, van Oyen $\mathrm{H}$ et al (2009) The reliability of the Minimum European Health Module. Int J Public Health 54(2):55-60

Crimmins EM, Hayward MD et al (1996) Differentials in active life expectancy in the older population of the United States. J Gerontol B Psychol Sci Soc Sci 51(3):S111-S120

Ekholm O, Bronnum-Hansen H (2009) Cross-national comparisons of non-harmonized indicators may lead to more confusion than clarification. Scand J Public Health 37(6):661-663

European Commission (2009) Healthy ageing: keystone for a sustainable Europe-EU health policy in the context of demographic change. Discussion paper of the Services of DG SANCO, DG ECFIN and DG EMPL. Brusseles, DG SANCO, DG ECFIN and DG EMPL

European Commission (2010) European Commission-Health \& Consumer Protection Directorate-General (DG SANCO) developments on the EU structural indicators. http://ec.europa.eu/ health/ph_information/indicators/lifeyears_en.htm

European Observatory on Social Situation and Demography (2009a) Monitoring the social situation in Europe

European Observatory on the Social Situation-Demography Network (2009b) Demographic trends, socio-economic impacts and policy implications in the European Union-2008. Brussels, European Commission

Eurostat (2007) Comparative EU statistics on income and living conditions: issues and challenges. In: Proceedings of the EU-SILC conference (Helsinki, 6-8 November 2006). Methodologies and working papers. Luxembourg, Eurostat

EUROSTAT (2009) Comparative final EU quality report 2006 (Version 3-October 2009). Luxembourg, European Commission: $1-63$

Human Mortality Database (2010) University of California, Berkely (USA) and Max Planck Institute for Demographic Research (Germany)

Jagger C (1999) Health expectancy calculations by the Sullivan method: a practical guide. Nikon University, Tokyo

Jagger C, Gillies C et al (2010) The global activity limitation index measured function and disability similarly across European countries. J Clin Epidemiol 63:892-899

Jagger C, Gillies C et al (2008) Inequalities in healthy life years in the 25 countries of the European Union in 2005: a cross-national meta-regression analysis. Lancet 372(9656):2124-2131

Leveille SG, Resnick HE et al (2000) Gender differences in disability: evidence and underlying reasons. Aging (Milano) 12(2):106-112

Mathers CD, Robine JM (1997) How good is Sullivan's method for monitoring changes in population health expectancies? J Epidemiol Community Health 51(1):80-86

McKee M, Shkolnikov V (2001) Understanding the toll of premature death among men in eastern Europe. BMJ 323(7320):1051-1055 
Merrill SS, Seeman TE et al (1997) Gender differences in the comparison of self-reported disability and performance measures. J Gerontol A Biol Sci Med Sci 52(1):M19-M26

Newey C, Nolte E et al (2003) Avoidable mortality in the enlarged European Union, Institute des Sciences et de Sante, Paris

Nusselder WJ, Looman CW (2004) Decomposition of differences in health expectancy by cause. Demography 41(2):315-334

Oksuzyan A, Juel K et al (2008) Men: good health and high mortality. Sex differences in health and aging. Aging Clin Exp Res 20(2):91-102

Oksuzyan A, Petersen I et al (2009) The male-female healthsurvival paradox: a survey and register study of the impact of sex-specific selection and information bias. Ann Epidemiol 19(7):504-511

Pollard JH (1988) On the decomposition of changes in expectation of life and differentials in life expectancy. Demography 25(2): 265-276

Robine JM, Jagger C (2003) Creating a coherent set of indicators to monitor health across Europe: the Euro-REVES 2 project. Eur J Public Health 13(3 Suppl):6-14

Robine JM, Michel JP et al (1992) Measurement and utilization of healthy life expectancy: conceptual issues. Bull World Health Organ 70(6):791-800
Robine J, Jagger C et al (2003) Determining health expectancies. West Sussex, UK, Wiley

Spiers N, Jagger C et al (2003) Are gender differences in the relationship between self-rated health and mortality enduring? Results from three birth cohorts in Melton Mowbray, United Kingdom. Gerontologist 43(3):406-411; discussion 372-405

Sullivan DF (1971) A single index of mortality and morbidity. HSMHA Health Rep 86(4):347-354

Trovato F, Lalu NM (1998) Contribution of cause-specific mortality to changing sex differences in life expectancy: seven nations case study. Soc Biol 45(1-2):1-20

Van de Water HP, Boshuizen HC et al (1995) Health expectancy: an indicator for change? J Epidemiol Community Health 49(3): 330-331

Van Oyen H, Van der Heyden J et al (2006) Monitoring population disability: evaluation of a new Global Activity Limitation Indicator (GALI). Soz Praventivmed 51(3):153-161

Verbrugge LM (1989) The twain meet: empirical explanations of sex differences in health and mortality. $J$ Health Soc Behav 30(3):282-304

VWS (2008) Naar een weerbare samenleving. Beleidsplan aanpak gezondheidsverschillen op basis van sociaaleconomische achtergronden. Den Haag, VWS 